Original Article

\title{
THE EFFECT OF GOVERNMENTAL LAWS AND PHARMACEUTICAL ETHICS ON BUILDING A DISTINCTIVE RELATIONSHIP BETWEEN PHARMACISTS AND THEIR CUSTOMERS
}

\author{
MAYSOON ABDELMALEK (ABUJARAD ALHUWITAT)
}

Independent Pharmacist Researcher, Member of Jordanian Pharmacist Association, Aljubiha, University Street, Amman, Jordan Email: nejemward@yahoo.com

Received: 01 Jul 2020, Revised and Accepted: 28 Sep 2020

\section{ABSTRACT}

Objective: This study aimed to investigate the effect of governmental laws and pharmaceutical ethics on building a distinctive relationship between pharmacists and their customers from the perspective of pharmacists in Jordan through measuring the customers' satisfaction and their perceived value.

Methods: This study is a descriptive and correlative one. A self-administrated questionnaire was distributed to a random sample of 110 pharmacists working in private pharmacies to measure the effect of governmental laws and pharmaceutical ethics on building a distinctive relationship between pharmacists and customers.

Results: ANOVA-test showed a significant effect of governmental laws and pharmaceutical ethics on building a distinctive relationship between pharmacists and their customers $(p=0.003)$ and on the customer-perceived value $(p=0.00)$. Multiple regression analysis showed a significant effect of the application of ethical standards on building a distinctive relationship between pharmacists and their customers ( $p=0.006$ ) and a significant effect of both dimensions: (application of laws and regulations) and (application of ethical standards) on customer-perceived value ( $\mathrm{p}=$ $0.004, p=0.009$ ) respectively. Moreover, there was a statistically significant effect of the application of ethical standards on customers' satisfaction $(\mathrm{p}=0.03)$.

Conclusion: Based on the results of this study, there should be an effort by the government and the private institutions responsible for the pharmacy profession in Jordan to contribute to build a distinctive relationship between pharmacies and their customers, as this relationship increases the perceived value and satisfaction of customers.

Keywords: Governmental laws, Pharmaceutical ethics, Customer-perceived value, Customers' satisfaction, Jordan

(C) 2020 The Authors. Published by Innovare Academic Sciences Pvt Ltd. This is an open access article under the CC BY license (http://creativecommons.org/licenses/by/4.0/) DOI: http://dx.doi.org/10.22159/ijpps.2020v12i11.38908. Journal homepage: https://innovareacademics.in/journals/index.php/ijpps.

\section{INTRODUCTION}

The professional laws, in all fields, have a great importance in preserving nations and societies, as they include principles and rules governing human behavior, increasing individuals' commitment to their professions, and directing them to achieve their organizations aims and objectives [1]. Nevertheless, professional laws are not enough to realize the organizations' strategies without voluntary commitment from the employees towards their organizations [2]. Such a commitment should be supported by ethics of employees. Therefore, professional laws issued by governments or organizations associated with employees' ethics are considered very critical to achieve the employees's commitment that leads to their job satisfaction, loyalty, as well as their organizations' success and sustainability. Once pharmacists became satisfied in their work, this would reflect positively on their relationship with their customers. The success of the relationship between pharmacists and their customers is evaluated by customers' satisfaction [3].

Although all professions have common laws and ethics that are critical for organizations and employees, each profession has its literature [4]. Particularly, in the pharmaceutical field, etiquette required by a pharmacist may be greater than that required in other occupations; this is because the etiquette of the pharmacist is related to the health and life of human. Pharmacists are recognized as the most eligible healthcare professionals to advise patients on health products and to provide evidence-based drug information [5]. The distinctive relationship between pharmacists and patients plays an important part in providing physical and emotional support for patients and in increasing their adherence to medication [6]. On the contrary, lack of a good relationship between pharmacists and patients affects health behavior of patients, such as conformity to medication [7].

Pharmacy was once known as a science of investigating drugs, their characteristics, formulation and manufacturing. Currently, and after the evolution in science, information technology and industrial technology, many new and important specializations, branching off from the science of pharmacy in the fields of economy and business, have emerged [8]. Hence, we should pay attention to two principal factors, in order to keep the profession of pharmacy in Jordan in the right direction. Those two factors are represented in the ethics and laws that govern this profession, primarily aiming at providing the community with health care.

Through her personal experience and depending on different interviews conducted with the members of Jordan pharmacists' Association (JPA), Jordan food and drug administration (JFDA) and the Ministry of health in Jordan (MHJ), the researcher has found many missing laws that are important to develop the profession of pharmacy in Jordan, to build a good relationship between employers in the private pharmaceutical sector and their customers, and to spur a vital role in enriching the economic aspect. Moreover, many pharmacists in Jordan are still unaware of such laws related to protecting and developing the profession of pharmacy. This indicates that the Jordanian Pharmacists Association (JPA) has to devote much effort to raise its members awareness of their rights and familiarize them with the laws that guide them to build a good relationship with their customers. Therefore, the current study aims to evaluate the current level of governmental laws and professional ethics, including (laws and regulations, occupational training, ethical standards, awareness-raising campaigns, and monitoring and inspection) applied in Jordanian pharmaceutical sector, in addition, to investigate the effect of these factors on building a distinctive relationship between pharmacists and customers through customers' satisfaction and their perceived value.

\section{MATERIALS AND METHODS}

\section{Study method}

To achieve the study objective that is embedded in recognizing factors that may influence the building of a distinctive relationship between 
pharmacists and their customers, the study used the correlative descriptive approach. In this way, data was collected through the study tool (questionnaire) filled by the pharmacists of the study sample. Then, the collected data were analyzed using a set of statistical techniques for the statistical package of social science (SPSS).

\section{Study population}

The study population consisted of the private pharmacies' sector in different areas of the capital "Amman" with a number of (1473) pharmacies according to the records of (JPA) for the year of 2020.

\section{Inclusion criteria}

Pharmacists who have at least bachelor's degree in pharmaceutical science.

Pharmacists with at least one year of experience in the field of pharmaceutical sector.

Pharmacists who are included in (JPA).

\section{Exclusion criteria}

Pharmacists who do not meet the above criteria were excluded from the study population.

Pharmacists who have no interaction with customers in their work in pharmacies.

\section{Study sample}

The study used a simple random sample of pharmacists working in the pharmaceutical sector in Amman city. (110) copies of the study questionnaire were distributed, (102) were retrieved, and (4) were excluded from the retrieved number owing to their invalidity for analysis. Therefore, (98) questionnaires were applied for data analysis.

\section{Data collection sources}

The data of the study was obtained from second and primary sources, as follows:

\section{Secondary sources}

Data that were obtained from library resources, literature review and internet resources of related studies to create scientific foundations and theoretical framework of the current study.

\section{Primary resources}

Data that were obtained through the study questionnaire as a tool suitable for all variables of the study topic, in order to address the analytical parts of the study topic in accordance with the suggested model in the study.

\section{Study tool}

A questionnaire was developed in order to detect factors influencing the building of a distinctive relationship between pharmacists and their customers from the perspective of pharmacists. Therefore, it consisted of two basic themes: the first theme is the role of governmental laws and pharmaceutical ethics, whereas the second theme is building the relationship between pharmacists and customers.

The questionnaire, in its initial version, was composed of (56) items that were selected based on the literature, eight items for each dimension, then it was presented to a number of academic arbitrators for the purpose of evaluating its items appropriateness to their variables, language structure, items consistency, etc. Accordingly, eight items were excluded, and six items were modified. Hence, the final version of the questionnaire consisted of (48) items.

\section{RESULTS}

Cronbach's Alpha Coefficient was used to make sure that the questionnaire measures the factors to be measured, proves its validity through measuring internal consistency among the items of each dimension. When Cronbach's Alpha Coefficient is found greater than (0.60), it can be said that the study instrument reliability is acceptable [9].

It can be noted from the table above (table 1) that Cronbach's Alpha Coefficient for the instrument scale is (0.87), which indicates that the instrument scale can be described by reliability. Also, Cronbach's Alpha Coefficient for all variables ranges between (0.623) and (0.821), which means that the data collected to measure the instrument's variables are reliable.

According to the literature review that confirms the effect of governmental laws and pharmaceutical ethics on building a distinctive relationship between pharmacists and their customers and the reliability statistics of all instrument dimensions, the following study model can be suggested (fig. 1).

Table 1: Reliability statistics of the study dimensions

\begin{tabular}{llc}
\hline No. & Theme & Alpha( $\boldsymbol{\alpha})$ value \\
\hline 1 & Laws and regulations & 0.821 \\
2 & Occupational training & 0.789 \\
3 & Ethical standards & 0.623 \\
4 & Awareness-rising campaigns & 0.714 \\
5 & Monitoring and inspection & 0.820 \\
6 & Perceived value & 0.796 \\
7 & Satisfaction & 0.702 \\
Total (instrument) & & 0.87 \\
\hline
\end{tabular}

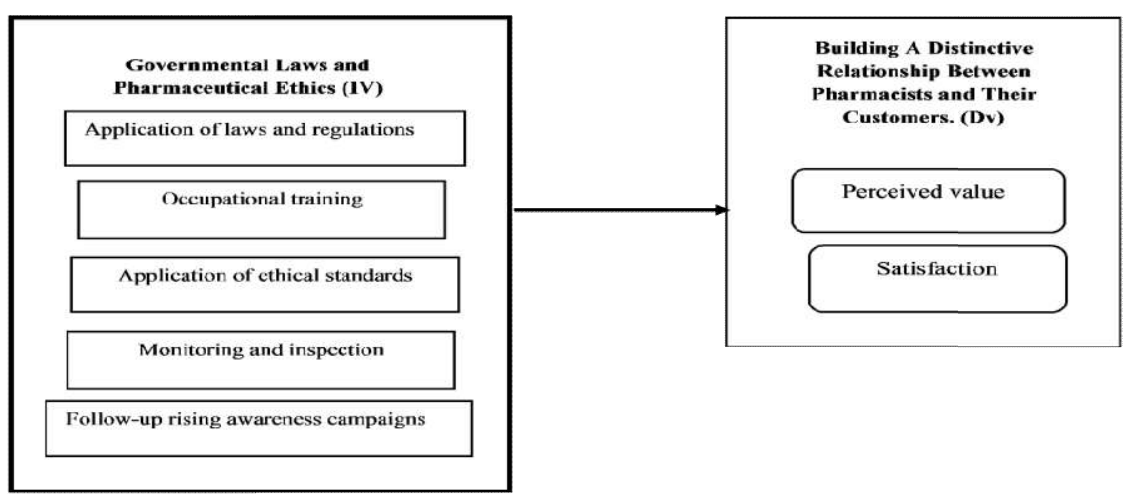

Fig. 1: Research suggested model 
Table 2: One-way ANOVA for regression to verify the effect of government laws and pharmaceutical ethics on building a distinctive relationship between pharmacists and their customers

\begin{tabular}{|c|c|c|c|c|c|c|}
\hline Statement & $\begin{array}{l}\text { Source of } \\
\text { variance }\end{array}$ & $\begin{array}{l}\text { Sum of } \\
\text { squares (SS) }\end{array}$ & $\begin{array}{l}\text { Degree of } \\
\text { freedom (df) }\end{array}$ & $\begin{array}{l}\text { Means } \\
\text { square (MS) }\end{array}$ & $\begin{array}{l}\text { (F) } \\
\text { statisic }\end{array}$ & $\begin{array}{l}\text { Level of } \\
\text { significance (sig) }\end{array}$ \\
\hline The effect of governmental laws and & Between groups & 3.839 & 5 & 0.768 & $3.950^{* *}$ & $0.003^{\mathrm{b}}$ \\
\hline pharmaceutical ethics on building a & Whithin groups & 18.074 & 93 & 0.194 & & \\
\hline $\begin{array}{l}\text { distinctive relationship between } \\
\text { pharmacists and their customer "from } \\
\text { the perspective of pharmacists" }\end{array}$ & Total & 21.913 & 98 & & & \\
\hline
\end{tabular}

*Dependent Variable: Building a distinctive relationship between pharmacists and their customers.

Testing the effect of governmental laws and pharmaceutical ethics on building a distinctive relationship between pharmacists and their customers from the perspective of pharmacists

Analysis of variance (ANOVA) for regression and multiple regression analysis has been used in order to verify the effect of governmental laws and pharmaceutical ethics on building a distinctive relationship between pharmacists and their customers from the perspective of pharmacists (table 2 and table 3 ).

Table (2) shows that ANOVA for regression is significant at the level of $(\alpha=0.05)$, where the (calculated F) is (3.950), which is greater than (Tabulated F) (2.65). The level of significance (0.003) is lower than $(0.05)$, indicating that the regression model is fit. This result indicates that "governmental laws and pharmaceutical ethics" has a significant effect on the level of $(a=0.05)$ on building a distinctive relationship between pharmacists and their customers from the perspective of pharmacists.

To identify the regression coefficient, multiple regression analysis was used for all factors of the independent variable to reveal its effect on the main dependent variable (table 3 ).
From the data illustrated in the table above (table 3 ), it is clear that there is a statistically significant effect for one variable (application of ethical standards) on building a distinctive relationship between pharmacists and their customers, where the level of significance is (0.006), which is less than the level of significance $(a=0.05)$, whereas the other variables are not statically significant in their effect on building a distinctive relationship between pharmacists and their customers. The correlation coefficient (R) is (0.419), and the coefficient of determination $\left(R^{2}\right)$ explains $(0.175)$ of the variance in the dependent variable, which means that a value of (\%17.5) of variations in building a distinctive relationship between pharmacists and their customers is generated by the change in "governmental laws and pharmaceutical ethics".

Testing the effect of governmental laws and pharmaceutica ethics on the dimensions of "distinctive relationship between pharmacists and their customers":

First: Testing the effect of governmental laws and pharmaceutical ethics on customer-perceived value

ANOVA for Multiple Regression was calculated for all factors of the independent variable to reveal its effect on customer-perceived value (table 4).

Table 3: (Coefficients) to test the effect of governmental laws and pharmaceutical ethics on building a distinctive relationship between pharmacists and their customers

\begin{tabular}{lllll}
\hline Model & \multicolumn{2}{c}{ Unstandardized coefficients } & Standardized coefficients & Sig. \\
\cline { 2 - 4 } & B & Std. error & Beta & 9.322 \\
(Constant) & 2.904 & .311 & & 0.000 \\
Application of laws and regulations & 0.100 & 0.064 & 0.172 & 1.567 \\
Occupational training & -0.070 & 0.060 & -0.141 & -1.182 \\
Application of ethical standards & 0.245 & 0.086 & $0.315^{* *}$ & 2.841 \\
Follow-uprising awareness campaigns & -0.012 & 0.067 & -0.024 & -0.184 \\
Monitoring and inspection & 0.040 & 0.075 & 0.063 & 0.006 \\
\hline
\end{tabular}

${ }^{*}$ Coefficient of determination $\left(\mathrm{R}^{2}\right)=0.175$, Coefficient of correlation $(\mathrm{R})=0.419,{ }^{* *}$ The effect is statistically significant at the level of $(\mathrm{a}=0.01)$

Table 4: One-way ANOVA for regression to verify the effect of governmental laws and pharmaceutical ethics on customer-perceived value

\begin{tabular}{llllll}
\hline Statement & $\begin{array}{l}\text { Source of } \\
\text { variance }\end{array}$ & $\begin{array}{l}\text { Sum of } \\
\text { squares (SS) }\end{array}$ & $\begin{array}{l}\text { Degree of } \\
\text { freedom (df) }\end{array}$ & $\begin{array}{l}\text { Means square } \\
\text { (MS) }\end{array}$ & $\begin{array}{l}\text { F-statistic } \\
\text { (sig.) }\end{array}$ \\
\hline $\begin{array}{l}\text { The effect of governmental } \\
\text { laws and pharmaceutical } \\
\text { ethics on customer }\end{array}$ & Between groups & 8.124 & 5 & 1.625 & 6.307 \\
perceived-value & Within groups & 23.957 & 93 & 0.258 & $0.000^{\mathrm{b}}$ \\
\hline
\end{tabular}

*Dependent variable: Customer perceived-value.

Table 5: Regression (Coefficients) to verify the effect of governmental laws and pharmaceutical ethics on customer-perceived value

\begin{tabular}{lllll}
\hline Model & \multicolumn{2}{l}{ Unstandardized coefficients } & Standardized coefficients & S \\
\cline { 2 - 4 } & B & Std. error & Beta & 7.700 \\
\hline (Constant) & 2.761 & 0.359 & & 0.000 \\
Application of laws and regulations & 0.215 & 0.074 & $0.305^{* *}$ & 2.918 \\
Occupational training & -0.135 & 0.069 & -0.223 & -1.968 \\
Application of ethical standards & 0.264 & 0.099 & $0.281^{* *}$ & 0.004 \\
Follow-up rising awareness campaigns & 0.062 & 0.077 & 0.101 & 0.052 \\
Monitoring and inspection & 0.000 & 0.086 & -0.001 & 0.009 \\
\hline
\end{tabular}

Coefficient of determination $\left(\mathrm{R}^{2}\right)=0.253$, coefficient of correlation $(\mathrm{R})=0.503$, ${ }^{* *}$ The effect is statistically significant at the level of $(\mathrm{a}=0.01)$. 
Table 4 indicates that ANOVA for regression is significant at the level of $(\alpha=0.05)$, where the (calculated F) (6.307) is greater than the (Tabulated F) (2.65), and the level of significance $(0.000)$ is less than $(0.05)$ indicating that the regression model is fit. This result also indicates that the "governmental laws and pharmaceutical ethics" factor has significant effect at the level of $(\mathrm{a}=0.05)$ on "customer-perceived value".

To identify the regression coefficient, multiple regression analysis was used for all factors of the independent variable to reveal its effect on customer perceived-value (table 5).

From the data illustrated in the table above (table 5), it is clear that there is a statistically significant effect for some dimensions of "governmental laws and pharmaceutical ethics" (application of laws and regulations and application of ethical standards) on "customerperceived value", where the level of significance for the two variables is $(0.004$ and 0.009$)$ respectively, which is less than the significance level of $(a=0.05)$, thereby it is statistically significant Other variables of "governmental laws and pharmaceutical ethics" have no significant effect on "customer-perceived value". The correlation coefficient (R) is (0.503), and the coefficient of determination $\left(\mathrm{R}^{2}\right)$ explains a ratio of $(0.253)$ of the variance in the dependent variable, which means that a value of (\%25.3) of variations in the "customer-perceived value" is generated by the change in the "governmental laws and pharmaceutical ethics".

Second: Testing the effect of governmental laws and pharmaceutical ethics on customer's satisfaction

One-way ANOVA for regression analysis was used to verify the effect of governmental laws and pharmaceutical ethics on customer's satisfaction (table 6).

Table 6: One-way ANOVA for regression to verify the effect of governmental laws and pharmaceutical ethics on customer's satisfaction

\begin{tabular}{|c|c|c|c|c|c|c|}
\hline Statement & $\begin{array}{l}\text { Source of } \\
\text { variance }\end{array}$ & $\begin{array}{l}\text { Sum of squares } \\
\text { (SS) }\end{array}$ & $\begin{array}{l}\text { Degree of } \\
\text { freedom (df) }\end{array}$ & $\begin{array}{l}\text { Mean } \\
\text { square (MS }\end{array}$ & $\begin{array}{l}\text { (F) } \\
\text { Statisic }\end{array}$ & $\begin{array}{l}\text { Level of } \\
\text { significance (Sig.) }\end{array}$ \\
\hline The effect of governmental laws and & Betwen groups & 3.546 & 5 & 0.709 & 1.813 & $0.118^{\mathrm{b}}$ \\
\hline pharmaceutical ethics on customer's & Within groups & 36.386 & 93 & 0.391 & & \\
\hline satisfaction. & Total & 39.932 & 98 & & & \\
\hline
\end{tabular}

*Dependent variable: customer's satisfaction

Table (6) shows that the Analysis of variance (ANOVA) for regression is not significant at the level of $(a=0.05)$, where the (Calculated-F) (1.813) is less than the (Tabulated F) (2.65), and the level of significance $(0.118)$ is greater than $(0.05)$ indicating that the regression model is not statistically significant. This result indicates that there is no statistically significant effect at the level of ( $a=0.05$ ) for governmental laws and pharmaceutical ethics on customer's satisfaction. To identify the regression coefficients, multiple regression analysis was used for all factors of the independent variable to indicate their effect on customer's satisfaction (table 7).

Table 7: Regression coefficients to verify the effect of governmental laws and pharmaceutical ethics on customer's satisfaction

\begin{tabular}{|c|c|c|c|c|c|}
\hline \multirow[t]{2}{*}{ Model } & \multicolumn{2}{|c|}{ Unstandardized coefficients } & \multirow{2}{*}{$\begin{array}{l}\text { Standardized coefficients } \\
\text { Beta }\end{array}$} & \multirow[t]{2}{*}{$\mathbf{t}$} & \multirow[t]{2}{*}{ Sig. } \\
\hline & B & Std. error & & & \\
\hline (Constant) & 3.035 & 0.442 & & 6.869 & 0.000 \\
\hline Application of laws and regulations & 0.068 & 0.091 & 0.087 & 0.753 & 0.453 \\
\hline Occupation training & -0.089 & 0.085 & -0.132 & -1.053 & 0.295 \\
\hline Application of ethical standards & 0.269 & 0.122 & 0.256 & 2.198 & 0.030 \\
\hline Follow-up rising awareness campaigns & 0.049 & 0.094 & 0.071 & 0.516 & 0.607 \\
\hline Monitoring and inspection & -0.025 & 0.106 & -0.029 & -0.237 & 0.813 \\
\hline
\end{tabular}

Coefficient of determination $\left(R^{2}\right)=0.089$, Correlation Coefficient $R=(0.298)$.

Table 7 shows that there is a statistically significant effect for the factor (Application of ethical standards) on customer's satisfaction, where the level of significance $(0.030)$ is less than the level of significance (0.05). The other variables of governmental laws and pharmaceutical ethics are not statically significant on customer's satisfaction. The multiple correlation coefficient (R) is (0.298), and the determination coefficient $\left(\mathrm{R}^{2}\right)$ explains $(0.089)$ of the variance in the dependent variable, indicating that $(8.9 \%)$ of variances in the customer's satisfaction results from the role of governmental laws and pharmaceutical ethics.

\section{DISCUSSION}

It has been noted that the main variable "governmental laws and pharmaceutical ethics", as a whole, significantly affect the distinctive relationship between pharmacists and their customers. This means that when pharmacists practice their work according to the governmental laws and regulations, the relationship with their customers will be monitored and controlled. In this manner, they have more legal liability and social responsibility towards their community. To be distinctive, pharmacists should put the relational customer's needs above their own, which will likely make their relational customers feel valued [10]. Also, when pharmacists behave in their work according to their professional ethics, they will get a better reputation increasing the customers' loyalty. This result confirms that once the pharmacists practice their work closed to the laws issued by the Ministry of Health in Jordan and Jordan pharmacists' Association, they will build a distinctive relationship with their customers. Nevertheless, practically, compared with some developed countries, the pharmaceutical sector in Jordan still needs enough laws that can control the professional behavior of pharmacists as well as protect them against some legal or social risks. When they were tested together, from all variables of the governmental laws and pharmaceutical ethics, "application of ethical standards" was found as the only factor affecting the relationship between the pharmacists and customers significantly. Although all other variables play an important role in building a distinctive relationship between pharmacist's and their customers, "application of ethical standards" factor has the most significant role in this relationship. This indicates that even though factors of the governmental laws and pharmaceutical ethics are available, they have a slight effect on the relationship between pharmacists and their customers, whereas "application of ethical standards" is considered as an agent of this relationship. This result is supported by the study conducted by Salari et al. [11], who mentiond that the code of pharmaceutical ethics provides pharmacists with principles of ethical conduct supporting them to build a robust relationship with their patients, many health care providers, and their community in general through their daily practice of the pharmaceutical profession.

This result shows the importance of including a set of pharmaceutical ethics in one pharmaceutical system approved by all 
pharmaceutical institutions representatives in Jordan; (JPA), (JFDA), and $(\mathrm{MHJ})$, and then adopted by all pharmacists in Jordanian public and private pharmacies. This ethical system should make Jordanian pharmacists be accountable to their community, customers, and authorities responsible for their profession. Compiling the code of ethics into the national pharmaceutical system is the first step in implementing ethics in pharmaceutical professional practice [12].

This result comes in consistence with Sharif et al.'s study [13], which found that compiling code of ethics and improving the curriculum of pharmacy ethics is highly significant to provide the best pharmaceutical care and to build a distinctive relationship with customers.

It has been noted that "governmental laws and pharmaceutical ethics", as a whole, in addition to the sub-dimensions (application of laws and regulations, application of ethical standards) have a significant effect on "customer-perceived value". This may be attributed to that when pharmacists seem to be committed to the application of laws and regulations and ethical standards, the customers' trust in the pharmacy will increase the active interaction between both pharmacists and customers. This interaction may manifest itself in many dimensions, such as medical consultancy, iterative medical prescriptions, medical treatments, etc. Such activities should be reflected in increasing the customer perceived value.

It has been noted that "governmental laws and pharmaceutical ethics", as a whole, as well as all its factors, except the factor "application of ethical standards," do not have a significant effect on the customer's satisfaction. The pharmaceutical behavior supported by ethical standards motivates strongly the customer's confidence in pharmacists, increasing his satisfaction in the pharmacy processes.

This indicates that when the pharmacist practices his profession ethically, the customer will feel that the pharmacist gives healthy patronage to customers and achieves their medical needs with accuracy and integrity. Assessment of patient's satisfaction is an approach to determine and track changes in his needs [14]. Therefore, this result can be used to conduct programs assessments for better services and maximize the professional capacity in pharmacies.

This result comes inconsistency with the findings of Tien study [12], which found that customers' trust and satisfaction significantly mediate the relationship between customers' loyalty and pharmacist's behavior. Also, this result comes inconsistency with the findings of Haque et al.'s study [15], which revealed a significant relationship between pharmaceutical marketing ethics and islamic marketing mechanism, which concurrently affects healthcare quality and patients' satisfaction positively. The results of the current study confirm the importance of establishing a comprehensive and pharmaceutical ethical system by the Ministry of health in Jordan and the Jordanian Pharmacist Association, as this significant system can protect the Jordanian pharmacists and keep their professional rights. Additionally, this cooperative pharmaceutical ethical system can provide customers with more health pharmaceutical rules and regulations that increase their perceived value and their satisfaction and loyalty.

\section{CONCLUSION}

Based on the results of this study, there should be an effort by the government and the private institutions responsible for the pharmaceutical profession to contribute cooperatively and collaboratively to build a distinctive relationship between pharmacists and their customers, especially as this distinctive relationship shows a significant effect on the perceived value and satisfaction of customers.

\section{LIMITATIONS}

The current study faced many limitations, such as the scarcity of studies conducted on the same topic in Jordan. Also, the current study used the questionnaire as a tool for data collection from the study sample. The questionnaire was completed by the pharmacists working in public and private pharmacies in Jordan. This implies that the data included in the study tool may be exposed to bias and partiality, although some arrangements to minimize this bias were made.

\section{ACKNOWLEDGMENT}

The researcher presents this research to all those who believe in her quest to build a better future for the pharmacy profession in Jordan, especially her children, and Prof. Nofal Al-Nu'man and $\mathrm{Dr}$ Mohammad M. Eseid.

\section{FUNDING}

Nil

\section{AUTHORS CONTRIBUTIONS}

Maysoon Abdelmalek "Abujarad Alhuwaitat" designed the study, collected the data, was involved in interpreting the data, and performed all the statistical analysis and writing the manuscript.

\section{CONFLICT OF INTERESTS}

Declared none

\section{REFERENCES}

1. Marmat G, Jain P, Mishra P. Understanding ethical/unethical behavior in pharmaceutical companies: a literature review. Int J Pharm Healthc Mark 2019;6:1-28.

2. Kalay F. The impact of organizational justice on employee performance: a survey in Turkey and Turkish context. Int J Hum Resour Stud 2016;6:41-54.

3. Mayun Gr, Indrasari M, Kusdhany LS. Relationship between patient's satisfaction of removable denture wearers and oral health-related quality of life. Int J Appl Pharm 2018;9:151-3.

4. Panigrahi SK, Alnashash HM. Quality work ethics and job satisfaction: an empirical analysis. Qual Access Success 2019;20:41-7.

5. Kwan D, Hirschkorn K, Boon HU. Canadian pharmacists' attitudes, knowledge, and professional practice behaviors toward dietary supplements: a systematic review. BMC Complement Altern Med 2006;6:1-10.

6. Ibrahim OM, Ibrahim R. Assessment of the current geriatric pharmaceutical care in the United Arab Emirates. Asian J Pharm Clin Res 2019;12:211-5.

7. Mahmudah RL, Ikawati Z, Wahyono D. A qualitative study of perspectives, expectations and needs of education in chronic obstructive pulmonary disease (COPD). Int J Curr Pharm Res 2017;9:32-5.

8. Hussain A, Ibrahim MI. Medication counseling and dispensing practices at community pharmacies: a comparative crosssectional study from Pakistan. Int J Clin Pharm 2011;33:85967.

9. Sekaran U, Bougie R. Research methods for business: a skillbuilding approach. $7^{\text {th }}$ ed. New York: John Wiley and Sons Inc 2016.

10. Abdullah Z, Ling TY, Sulaiman NS, Radzi RA, Putri KY. The effects of verbal communication behaviors on communication competence in the pharmaceutical industry. JCR 2020;7:697703.

11. Salari PO, Namazi H, Abdollahi M, Khansari F, Nikfar SH, Larijani $\mathrm{B}$, et al. Code of ethics for the national pharmaceutical system: codifying and compilation. J Res Med Sci 2013;18:442-8.

12. Dung LT. Pharmacist's interaction behavior and consumer loyalty: the mediating role of consumer trust and satisfaction. J Behav Sci 2019;14:1-13.

13. Sharif RS, Javadi M, Asghari F. Pharmacy ethics: evaluation pharmacists' ethical attitude. J Med Ethics Hist Med 2011;4:1-5.

14. Mahmoud AA. Patients' perspectives on the quality of pharmaceutical services in Saudi hospitals. Int J Res Pharm Sci 2016;6:36-40.

15. Haque A, Kabir SM, Tarofder AK, Chowdhury NA Pharmaceutical marketing ethics in healthcare quality for patient satisfaction: an Islamic approach. Int J Pharm Res 2019;11:1696-705. 